\title{
COMUNICACÃ̃
}

\section{Detecção de Myxomycetes em morangueiro no sul de Minas Gerais}

\author{
Natali Ribeiro ${ }^{1}\left[\right.$, Paulo Sérgio Torres Brioso ${ }^{1}[$
}

${ }^{1}$ Laboratório Oficial de Diagnóstico Fitossanitário (L.O.D.F.), Universidade Federal Rural do Rio de Janeiro, BR-465, Km 7, 23897-000, Seropédica, RJ, Brasil.

Autor para correspondência: Natali Ribeiro (natali.ribeiro22@gmail.com)

Data de chegada: 01/02/2018. Aceito para publicação em: 08/04/2019.

$10.1590 / 0100-5405 / 189721$

\section{RESUMO}

Ribeiro, N.; Brioso, P.S.T. Detecção de Myxomycetes em morangueiro no sul de Minas Gerais. Summa Phytopathologica, v.45, n.3, p.340-341, 2019.

Com a maior expressão econômica dentre as pequenas frutas no mundo, o morangueiro tem como principal entrave o fitossanitário. Objetivando identificar possíveis fitoparasitas associados ao cultivo de morangueiro, coletaram-se amostras sintomáticas, entre março e outubro do ano de 2016, no município de Estiva - MG. Foram observadas estruturas frutificativas no pecíolo das folhas de 'Minas' e em microscópio estereoscópico e ótico, foi possível identificar o Myxomycetes, Diachea leucopoda nas amostras sintomáticas. Este é o primeiro registro do mesmo no Estado de Minas Gerais. Possivelmente, esse Myxomycetes tenha entrado nessa região devido à constante aquisição de mudas de outros Estados e até mesmo de outros países, tornando necessário maior rigor quanto à aquisição dessas mudas.

Palavras-chave: Fragaria x ananassa; Diachea leucopoda; Esporoteca.

\section{ABSTRACT}

Ribeiro, N.; Brioso, P.S.T. Detection of Myxomycetes in strawberry in the South of Minas Gerais. Summa Phytopathologica, v.45, n.3, p.340$341,2019$.

Showing the greatest economic expression among small fruits in the world, the strawberry has as main obstacle the phytosanitary issues. Aiming to identify possible phytoparasites associated with strawberry cultivation, symptomatic samples were collected between March and October 2016, in the city of Estiva - MG. Fruiting structures were observed in the leaf petiole of 〈Minas〉 and, under stereoscopic and optical microscopes, the Myxomycetes Diachea leucopoda could be identified in these symptomatic samples. This is its first record in Minas Gerais State. Possibly, this Myxomycetes has entered this region due to constant acquisition of seedlings from other States and even from other countries, evidencing the need for more strict rules for the purchase of seedlings.

Keywords: Fragaria x ananassa; Diachea leucopoda; Sporotheca

O morangueiro, Fragaria x ananassa Duch., é a espécie do grupo das pequenas frutas de maior expressão econômica no mundo. É uma cultura com alta suscetibilidade a pragas e doenças, sendo este o fator que mais restringe sua produção, uma vez que limitam a obtenção de altos rendimentos. No Brasil, as doenças de maior importância na cultura do morangueiro são as de origem bacteriana, fúngica e viral (8).

Embora, no mundo, em morangueiro sejam assinalados pelo menos três bactérias, dois chytrídeos, 17 (16 grupos e uma espécie) fitoplasmas, 105 fungos, dois myxomycotas, 50 nematóides, 15 straminipilas e 26 vírus, esses números crescem a cada ano e as interações destes fitopatógenos têm aumentado consideravelmente à medida que novas cultivares e/ou cultivares exóticas suscetíveis a estes fitopatógenos têm sido introduzidas nas áreas de cultivo desta espécie vegetal (9).

Levantamentos atualizados sobre fitopatógenos em morangueiro no sul de Minas Gerais, principal região produtora de morango do Brasil, são escassos e se limitam à informação sem comprovação científica ou que se baseiam exclusivamente na sintomatologia apresentada pela hospedeira ou em informações bibliográficas gerais que são extrapoladas para uma região de cultivo.

Desta forma, objetivando identificar possíveis fitoparasitas associados ao cultivo de morangueiro na região sul do Estado de Minas Gerais (9), de março a outubro de 2016, foram coletadas em lavoura de morangueiro no Sítio Dois Irmãos, bairro Olaria, na cidade de Estiva (MG), amostras sintomáticas de morangueiro 'Minas', as quais foram depositadas em envelopes de papel, armazenadas em recipiente com gelo, lacradas e levadas para o Laboratório Oficial de Diagnóstico Fitossanitário (L.O.D.F.) da UFRRJ.

Observamos ao microscópio estereoscópico Willd, a presença de estruturas frutificativas no pecíolo de folhas de morangueiro 'Minas' (Figura 1), sendo preparadas lâminas em lactofenol de amann com azul de algodão e observadas ao microscópio ótico Olympus BX 41 para a identificação morfológica. Foram visualizadas esporotecas pediceladas e esporos de coloração marrom clara. A partir da chave dicotômica descrita por Cavalcanti (1) foi possível identificar o Myxomycetes, Diachea leucopoda nestas amostras.

Segundo o Index Fungorum (4) e a revisão de Leontyev et al. (6), o gênero Diachea pertence ao Domínio Eukarya, Superreino Amoebozoa, Reino Protozoa, Filo Amoebozoa, Subfilo Conosa, Infrafilo Eumycetozoa, Subclasse Columellomycetidae, Classe Myxomycetes, Ordem Stemonitales, Família Incertae Sedis $(4,6)$. 

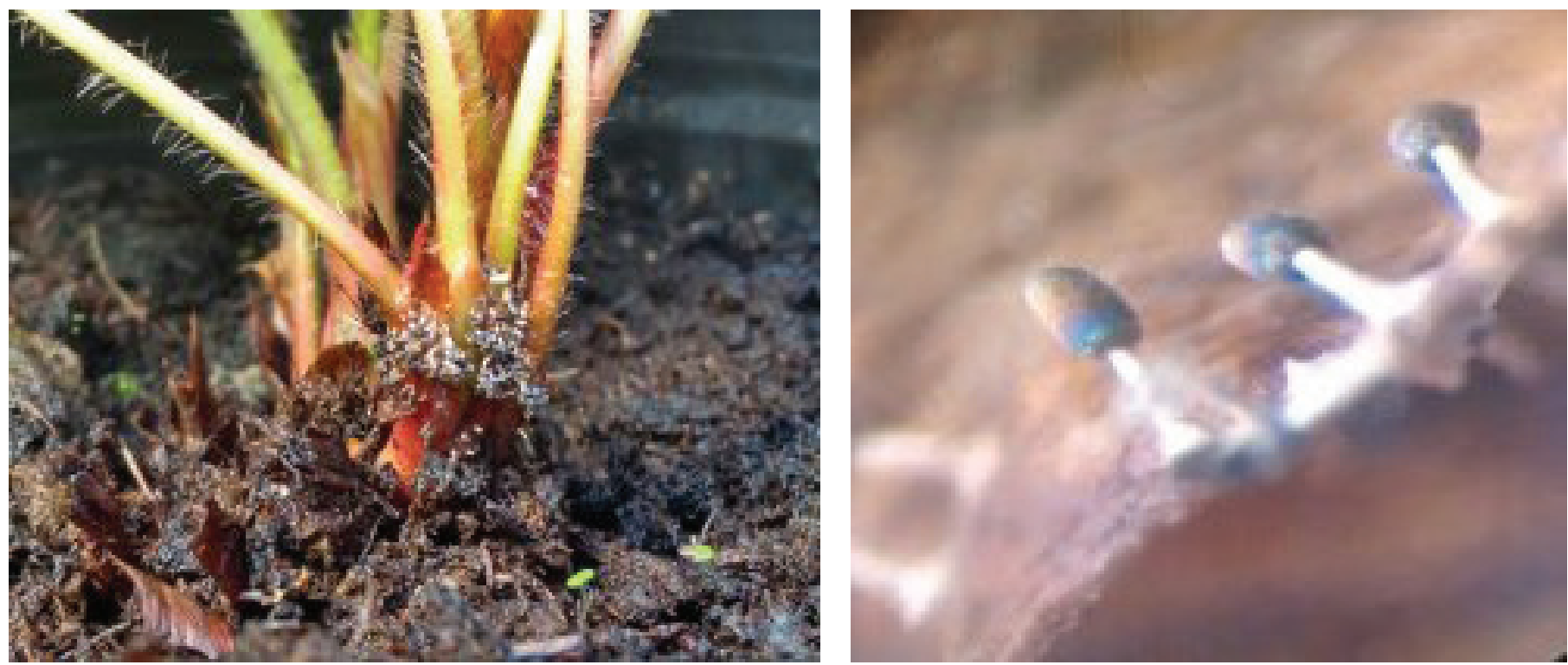

Figura 1. Myxomycetes detectado no pecíolo de folhas de morangueiro 'Minas' no sul de Minas Gerais.

Atualmente, são conhecidas no mundo pelo menos 19 espécies de Diachea (4) sendo que três dessas já foram citadas no Brasil, ou seja, D. bulbillosa (Berk. \& Broome) Lister, 1898; D. leucopoda (Bull.) Rostaf., 1874; D. silvaepluvialis M. L. Farr., $1969(1,4)$.

D. leucopoda já foi citada em fragmentos secos de mata no Paraná, Rio Grande do Norte, São Paulo; em folhas secas de Carnaúba [Copernicia prunifera (Mill.) H.E. Moore] no Piauí, em folhas de Mangue Botão (Conocarpus erectus L.), de Mangue Branco [Laguncularia racemosa (L.) C. F. Gaertn.] em Pernambuco; em folhas de morangueiro (Fragaria $x$ ananassa) 'Camino Real' em São Paulo $(1,2)$.

Keller \& Everhart (5) descrevem que os myxomicetos ocorrem com frequência em folhas secas, galhos em decomposição e grama usada como cobertura morta sob condições ideais de umidade e temperatura, podendo também, formar corpos de frutificação sobre plantas vivas. Porém, não promovem penetração de tecidos vegetais e também não produzem sintomas, não sendo considerados patógenos de plantas. Entretanto, quando ocorrem em partes comestíveis da planta, estas tornam se pouco apetecíveis e não comestíveis

D. leucopoda tem sido associada a 16 plantas hospedeiras distribuídas em diversos países sendo que, até o momento, só foi citado em plantas de Fragaria x ananassa oriunda da Alemanha, Brasil, Canadá, Coréia e Estados Unidos (2, 3, 7).

A presença deste Myxomycetes na região sul de Minas Gerais em morangueiro se constitui num primeiro registro do mesmo nesse Estado. Sua presença, apesar de não ser considerado um fitopatógeno, pode ocasionar perdas se encontrado nos frutos e também, em alta incidência, provocar diminuição da taxa fotossintética da planta. Mais estudos seriam necessários para avaliar os possíveis danos para a cultura do morangueiro.

\section{REFERÊNCIAS}

1. Cavalcanti, L.H.; Bezerra, A.C.C.; Costa, A.A.A.; Ferreira, I.N.; Bezerra, M.F.A. Distribution of Diachea (Didymiaceae, Myxomycetes) in the northeastern region of Brazil. Mycotaxon, Portland, v.110, p.163-172, 2009.

2. Domingues, R.J.; Tofoli, J.G.; Ferrari, J.T.; Nogueira, E.M.C. Primeiro regf istro de ocorrência de Diachea leucopoda (Bull.) Rostaf. (1874) em cultivo de morangueiro no Brasil. Documento Técnico do Instituto Biológico de São Paulo, São Paulo, n.15, p.1-9, 2012.

3. Gerlach, W.; Nirenberg, H. Occurrence of the slime mould Diachea leucopoda on strawberry and fuchsia in Germany on strawberry and fuchsia in Germany. Nachrichtenblatt des Deutschen Pflanzenschutzdienstes, Quedlinburg, v.32, n.12, p.179-180, 1980.3

4. Fungorum, Index. Index Fungorum. Wallingford: CABI, CBS and Landcare Reasearch (custodians), 2017. Disponível em: <http://www. indexfungorum.org/Names/NamesRecord.asp?RecordID=120783> Acesso em: 04 out. 2017.

5. Keller, H. W.; Everhart, S. E. Importance of Myxomycetes in Biological Research and Teaching. In: Papers in Plant Pathology. Lincoln, 2010. v. 3:1. Disponível em: <http://digitalcommons.unl.edu/plantpathpapers/366>. Acesso em: 04/05/2019.

6. Leontyev, D. V.; Schnittler, M.; Stephenson, S.; Novozhilov, Y. K.; Shchepin, O. N. Towards a phylogenetic classification of the Myxomycetes. Phytotaxa, Auckland, New Zealand, v.399, n.3, p.209-238, 2019.

7. Louisiana State University. Bernard Lowy Mycological Herbarium: Diachea leucopoda. Baton Rouge, 1966. Disponível em: <http://mycoportal. org/portal/collections/individual/index.php?occid=2377862. $>$ Acesso em: 22 out. 2017

8. Reis, A.; Costa, H. Principais doenças do morangueiro no Brasil e seu controle. Brasília: Embrapa Hortaliças, 2011. 9p. (Circular Técnica, 96).

9. Ribeiro, N. Levantamento de doenças e dinâmica populacional do ácaro-rajado na cultura do morangueiro no sul de Minas Gerais. 2017 66f. Dissertação (Mestrado em Fitossanidade e Biotecnologia Aplicada) - Instituto de Ciências Biológicas e da Saúde, Universidade Federal Rural do Rio de Janeiro, Seropédica. 